\title{
Delirium in children
}

under two years of age admitted to intensive

care units - a systematic review

\section{Monica Yvon Holberg}

Nyfødtsykepleier

Nyfødtintensiv avdeling, Oslo universitetssykehus

\section{Marie Hamilton Larsen}

Barnesykepleier og førsteamanuensis

Lovisenberg diakonale høgskole

\section{Kari Larsen Mariussen}

Spesialbibliotekar

Lovisenberg diakonale høgskole

\section{Nina Margrethe Kynø}

Barne- og intensivsykepleier og førsteamanuensis

Lovisenberg diakonale høgskole og Oslomet - storbyuniversitetet

Systematic review

\section{Summary}


Background: Delirium is a state of acute confusion that may arise in people of all ages. Sick infants (children $<12$ months old) and children under two years of age are a vulnerable patient group because they are cognitively immature and wholly or partly devoid of verbal language. They are thus dependent on the ability of health professionals and parents or families around them to observe changes in their condition. There is a need for health professionals to increase their knowledge of the prevalence, symptoms, risk factors and observations of delirium in this patient group.

Objective: To shed light on the prevalence, symptoms and observations of delirium in sick infants and children under two years of age admitted to a neonatal or paediatric intensive care unit, and the assessment tools used.

Method: Systematic literature review.

Results: Eight studies were included, with a total of 992 children under two years of age. The prevalence of delirium varied from 8 to $64 \%$. Symptoms of delirium were found to be agitation, confusion, inconsolability, hyperactivity, and altered sleep-wake cycles. Risk factors include respiratory therapy, age < two years and certain medications. Three assessment tools were reviewed: the PreSchool Confusion Assessment Method for the ICU (psCAM-ICU), the Cornell Assessment of Paediatric Delirium (CAPD), and the Paediatric Delirium component (PD scale) of the Sophia Observation Withdrawal Symptoms scale (SOS-PD scale), all with high validity, specificity and sensitivity.

Conclusion: Infants and children under two years of age can develop delirium, but the prevalence is uncertain. Delirium has specific symptoms. Education on the symptoms of delirium and use of assessment tools for health professionals who work in neonatal and paediatric ICUs can help to ensure that delirium is recognised and treated more promptly.

Delirium is a state of acute confusion that can occur in people of all ages. In adult ICUs, delirium is associated with higher mortality, extended ICU and hospital stays, cognitive impairment and reduced quality of life after ICU stays, as well as higher hospital costs (1). 
Sick infants (children $<12$ months) and children under two years of age are a vulnerable patient group because they are cognitively immature and wholly or partly devoid of verbal language. During their stays in neonatal or paediatric ICUs, they are therefore dependent on health professionals and parents being able to observe changes in their condition (2) and detect incipient delirium. There are limited studies of the prevalence of delirium in sick infants and children under two years of age (2).

\section{Symptoms of delirium}

Delirium follows a fluctuating course, and systematic observation of a child may be difficult (1). It may be difficult to detect whether the child's cognitive state has changed (2).

In addition, healthcare professionals' lack of awareness that such small children can develop delirium means that they do not receive the right therapy. In this situation, delirium can be a reflection of ongoing damage to an immature, vulnerable brain, which highlights the importance of prevention and diagnosis (3).

Symptoms of delirium may be misinterpreted for other conditions, which may lead to unnecessary testing, poorer neurological outcomes and extended hospital stays $(3,4)$. Delirium also leads to increased mortality $(5,6)$.

As a result of advances in medical treatment and technical equipment, more premature and seriously ill neonates survive (7). This means that more sick infants and children under the age of two may spend lengthy periods of time in neonatal or paediatric ICUs. If health professionals are to be optimally equipped to give these children the right therapy, they must have up-to-date knowledge of delirium and its symptoms. 
As far as it has been possible to investigate, review articles on delirium in children in this age group have not been published previously. Summaries of knowledge can improve practice (8). It seems relevant to systematically shed light on an area on which there has been little research, but which has major consequences for children and parents (9).

\section{Diagnosing delirium}

Diagnosing delirium in infants and children under two years of age can be difficult. A knowledge of normal age development is a prerequisite for being able to detect symptoms of delirium (10). The gold standard for diagnosing delirium is having a paediatric psychiatrist consult and assess the child (11).

The diagnostic criteria in 'Diagnostic and Statistical Manual of Mental Disorder' (DSM-IV) include (a) disturbed attention, (b) disturbances that develop over a short period of time, (c) disturbed cognition, (d) disturbances in points $a$ and $b$ that cannot be explained by a known neurocognitive disorder, or (e) the condition cannot be explained as due to another medical condition, intoxication, withdrawal, other exposure to a toxin or having multiple aetiologies (11).

Delirium is divided into three groups (Table 1) $(9,12)$. Assessment tools for adults have been developed on the basis of these criteria (13). These in turn have been modified for the age group in question, as support for daily observation of the condition of the child.

Table 1. Types of delirium, symptoms and consequences

\begin{tabular}{|c|c|c|c|}
\hline Sub-groups & Hyperactive delirium & Hypoactive delirium & Mixed delirium \\
\hline Symptoms & $\begin{array}{l}\text { - Anxious } \\
\text { - Fretful } \\
\text { - Agitated } \\
\text { - No eye contact }\end{array}$ & $\begin{array}{l}\text { - Quiet } \\
\text { - Sluggish } \\
\text { - Inattentive } \\
\text { - No eye contact } \\
\text { - Withdrawn }\end{array}$ & $\begin{array}{l}\text { - Mixture of symptoms of } \\
\text { hyper- and hypoactive } \\
\text { delirium } \\
\text { - The child may show } \\
\text { symptoms of hyperactive } \\
\text { delirium and a short time } \\
\text { later have symptoms of } \\
\text { hypoactive delirium }\end{array}$ \\
\hline Consequences & $\begin{array}{l}\text { - Risk of extubation or } \\
\text { self-removal of intravenous } \\
\text { cannulae and other } \\
\text { medical equipment }\end{array}$ & $\begin{array}{l}\text { - Less probable that the } \\
\text { child harms itself }\end{array}$ & \\
\hline
\end{tabular}




\section{Factors that predispose for delirium}

Agitation means psychomotor restlessness and hyperactivity and is the symptom most frequently reported when delirium is suspected. Hypoactive delirium, on the other hand, appears to be underrecognised for this patient group $(9,12)$.

Predisposing factors that increase the chances of delirium developing are age, cognitive development, behavioural development, previous functional level and morbidity. Other factors involved are complex and severe disease, pain, sedation, drugs such as benzodiazepines and opiates, withdrawal and complications and infections associated with invasive catheters.

Sensory deprivation, overstimulation and sleep deprivation increase the risk. Factors that contribute to maintaining delirium are continued exposure to predisposing factors, immobility, disturbances in sleep-wake cycles and lack of a familiar and secure environment (14).

Symptoms of pain, undersedation, withdrawal and delirium overlap, and may be difficult to distinguish from one another (15). Nurses in paediatric and neonatal ICUs are with the child twenty-four hours a day, and therefore have the opportunity to minimise factors that may precipitate or maintain delirium (16).

There is a need for health professionals to increase their knowledge of the prevalence, symptoms, risk factors and observations of delirium in sick infants and children under 2 years of age (17). Nurses in paediatric ICUs have proved to have an inadequate knowledge of how delirium develops, what therapy should be administered, and what assessment tools can be used (9). 
With greater knowledge of and attention to delirium in neonatal and paediatric ICUs, health professionals would be more readily able to detect children that have developed or are developing delirium, and provide appropriate treatment.

\section{The objective of the study}

The objective of this systematic review is to shed light on what the research literature reveals about prevalence, symptoms, observations, and the use of tools for assessing delirium in sick infants and children under two years of age who are admitted to neonatal or paediatric ICUs.

The research questions were as follows:

1. What does the research literature say about the prevalence of delirium in sick infants and children under two years of age?

2. Which symptoms are described as implying a diagnosis of delirium in this group?

3. Which observations and assessment tools are used in the included studies, and how are their validity and reliability evaluated?

\section{Method}

A systematic literature review of available research on the topic entails a methodical approach and reproducible search. It requires clear inclusion and exclusion criteria, and included studies must be subjected to quality review $(18,19)$.

A review must therefore both sum up the evidence base and interpret, weight and evaluate the evidence on which the article is based. In order to minimise systematic error and augment validity, the studies must be read and subjected to a quality review by at least two persons (8). 


\section{Search strategy}

The questions to be answered and inclusion and exclusion criteria (Table 2) were prepared with the aid of a PEO form (patient, exposure and outcome) (8). The patients were children aged o-2 years, the exposure was ICU treatment and being in a neonatal or paediatric ICU, and the outcome was delirium. A specialist librarian at Lovisenberg Diaconal University College devised a search strategy (Table 3) with a combination of keywords and text words to capture available data.

Following approval by the authors, the search strategy was adapted for each individual database. The systematic literature search was conducted on the databases Embase, Medline, Cinahl and Psycinfo on 5 November 2020.

We limited the search results to articles in English or a Scandinavian language, without restrictions on dates or study design. We chose the age group o-2 years, as articles often did not present the results for infants separately, and it was therefore not possible to extract enough data for a review article on infants specifically.

Table 2. Inclusion and exclusion criteria

\begin{tabular}{lll}
\hline & Inclusion criteria & Exclusion criteria \\
\hline P (Patient) & $\begin{array}{l}\text { Studies concerning sick infants and } \\
\text { children under two years of age }\end{array}$ & $\begin{array}{l}\text { Studies concerning children over two } \\
\text { years of age }\end{array}$ \\
\hline E (Exposure) & $\begin{array}{l}\text { Studies concerning intensive care } \\
\text { in neonatal or paediatric intensive } \\
\text { care units }\end{array}$ & $\begin{array}{l}\text { Studies from other contexts and other } \\
\text { types of treatment (for example anaes- } \\
\text { thesia, ECMO* treatment or cancer) }\end{array}$ \\
\hline O (Outcome) & $\begin{array}{l}\text { Studies concerning prevalence, symp- } \\
\text { toms, observations of delirium and } \\
\text { delirium screening tools }\end{array}$ & $\begin{array}{l}\text { Studies of anaesthesia } \\
\text { emergence delirium }\end{array}$ \\
\hline Design and language & Quantitative design & $\begin{array}{l}\text { Qualitative design and systematic } \\
\text { reviews }\end{array}$ \\
\hline Peer-reviewed studies & Academic papers, grey literature and \\
dissertations etc.
\end{tabular}


Table 3. Search strategy from Medline / Strategy for Medline search in Medline

\begin{tabular}{|c|c|}
\hline \multicolumn{2}{|l|}{ Search strategy } \\
\hline$\#$ & Search \\
\hline 1 & exp Delirium/ \\
\hline 2 & delir*.tw,kw. \\
\hline 3 & ((confusion or confused) adj3 (state* or acute)).tw,kw. \\
\hline 4 & 1 or 2 or 3 \\
\hline 5 & exp Intensive Care Units, Pediatric/ \\
\hline 6 & $\begin{array}{l}\text { (NICU or PICU or ((infant* or neonate* or neonatal or newborn* or new-born* } \\
\text { or premature or preterm or toddler* or pediatric* or paediatric* or children } \\
\text { or child) adj3 (intensiv* or ICU* or critical or critically))).tw,kw. }\end{array}$ \\
\hline 7 & $\begin{array}{l}\text { (exp Pediatric Nursing/ or exp Pediatrics/ or exp Infant/) and (intensiv* } \\
\text { or ICU* or critical or critically).tw,kw. }\end{array}$ \\
\hline 8 & 5 or 6 or 7 \\
\hline 9 & 4 and 9 \\
\hline 10 & limit 9 to (danish or english or norwegian or swedish) \\
\hline 11 & limit 10 to (comment or editorial or letter)* \\
\hline 12 & 10 not 11 \\
\hline
\end{tabular}

On completion of searches, three of the authors (MYH, MHL, NMK) read titles and abstracts. Each author included or excluded articles individually, and then disagreements were discussed until consensus was reached. For this first review, we used the screening tool Rayyan.

Exclusions were based on subject and/or age group. We read the remaining studies in full text, and included or excluded them on the basis of the applicable criteria (20).

We chose to include one case series, because case series describe complex, interesting, unknown or partly unknown conditions in a number of individuals, and reveal a need for further research. The treatment the study subjects receive in a case series is not compared with a control group, and is not necessarily the result of a random sample $(8,20,21)$.

The first and last authors read through the articles' reference lists and asked experts in the field about possible other publications without this yielding further results. The search process is illustrated in a PRISMA flow chart (Preferred Reporting Items of Systematic reviews and Meta-Analysis) (Figure 1). 


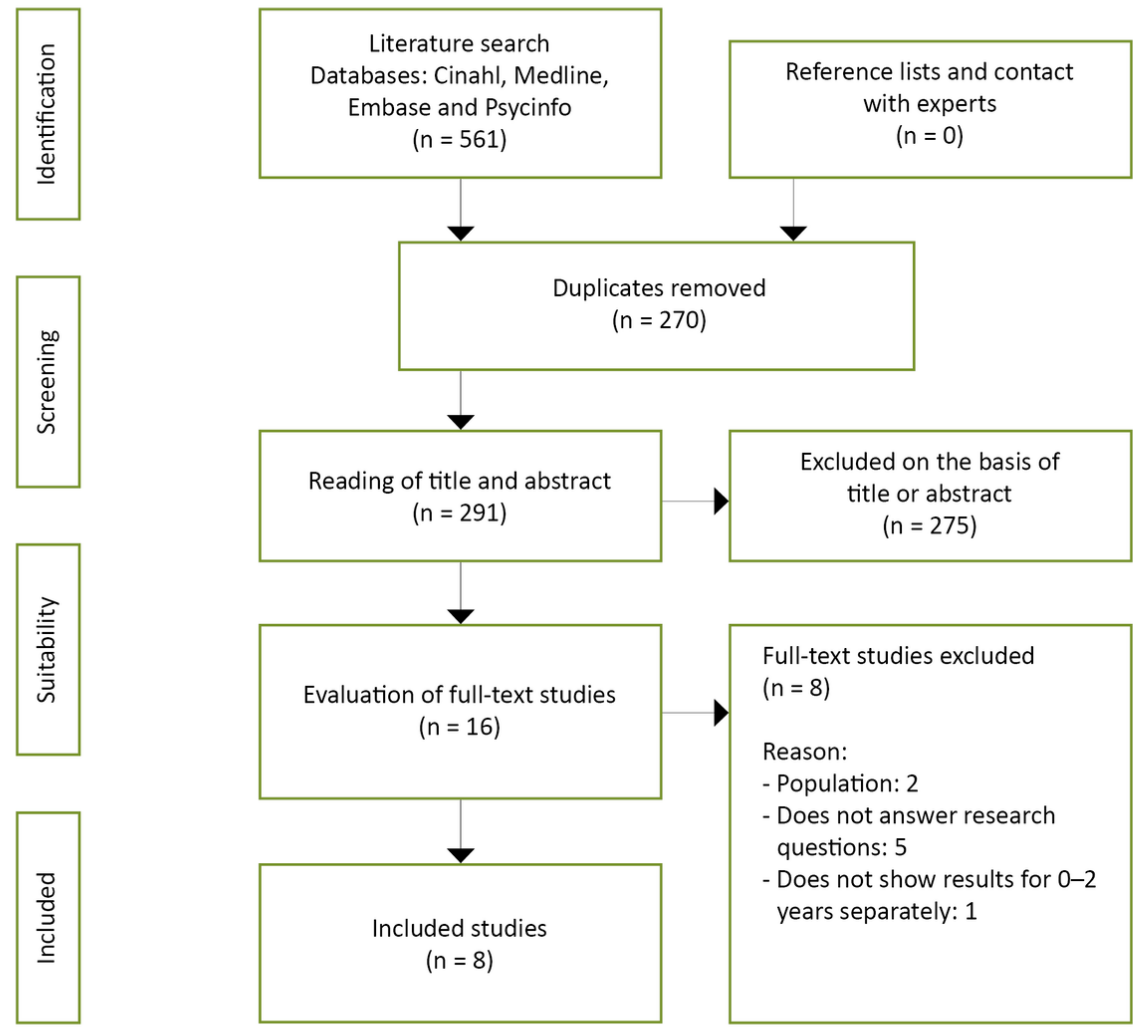

Adapted to Norwegian according to http://prisma-statement.org

\section{Quality review of included studies}

The first and last authors performed the quality review using study design checklists from the Joanna Briggs Institute (22).

The quality review was performed independently, and disagreements were resolved through discussion. We used the PRISMA checklist and flow chart to ensure high quality and to clarify and illustrate the literature search. The aim was to minimise systematic error (23).

\section{Results}

The literature search resulted in eight included studies. The studies were observation studies in the form of five cohort studies (one of which was a pilot study), a prevalence study, a double-blind diagnostic test study and a case series. Six of the studies were conducted and published in the US and two in the Netherlands, in the period 2007-2018. A total of 992 children under two years of age were included. 
Two of the studies were multi-centre studies $(24,25)$ while the remainder were conducted in one department. One study was conducted in a neonatal ICU (26), the others in paediatric ICUs. Five studies delivered results on prevalence $(24,25,27-29)$, a descriptive cohort study (30) and a case series (26) delivered results on symptoms, and three studies evaluated assessment tools $(25,28,31)$.

Two studies delivered results on both prevalence and assessment tools $(25,28)$. Central elements of the research questions are presented in the literature matrix (Appendix 1 [in Norwegian]).

\section{Prevalence of delirium}

Five studies delivered answers to the research question on the prevalence of delirium, which varied from 8.1 to 64 per cent.

Alvarez et al. (27) reported a prevalence of 64 per cent of delirium in infants in a paediatric cardiac ICU. Smith et al. (28) reported a prevalence of 53 to 56 per cent, depending on the assessment method used, in a paediatric ICU.

Silver et al. (29) reported a prevalence of 38.1 per cent, but only 34 children under two years of age took part in the study. Two studies reported a substantially lower prevalence: the study of Traube et al. (24) on 25 paediatric ICUs in five countries reported a prevalence of 13.5 per cent, and that of Ista et al. (25) on four paediatric ICUs found a prevalence of 8.1 per cent.

\section{Symptoms of delirium}

Groves et al. (26) describe symptoms of delirium in three patients in a neonatal ICU. The patients were born prematurely and had corrected gestational ages of 4,11 and 17 weeks at the time of observation. 
Schieveld et al. (30) describe the symptoms of nine children in a paediatric ICU. The symptoms of delirium in this patient group included agitation, fretfulness, anxiety, hyperactivity, inconsolability, altered or disturbed sleep-wake cycles, impaired attention and discomfort.

\section{Risk factors and important associations of delirium}

Three studies report potential risk factors for delirium. Alvarez et al. (27) wrote that prevalence increases with mechanical ventilation.

Traube et al. (24) also cited ventilator treatment as a risk factor in combination with an age of under two years. They described treatment with vasopressors and antiepileptics as a risk, along with being subject to physical restraint and a long stay in the ICU (24).

Silver et al. (29) also found a significant correlation between delirium and developmental delay, need for oxygen, use of mechanical ventilation and a deeper sedation level, all with a p-value of $<0.0001$. The children's ages were not controlled for in the analyses.

\section{Observations of and assessment tools for delirium}

Three studies supply answers to the research questions on observations and assessment tools. All were conducted in paediatric ICUs, two in doubleblind studies. Smith et al. (28) validated the pre-school Confusion Assessment Method for the ICU (psCAMICU), which was compared with the reference tool of the Diagnostic and Statistical Manual of Mental Disorders criteria (DSM-4), assessed by a paediatric psychiatrist.

Concrete validity was measured here as the ability of psCAM-ICU to diagnose presence or absence of delirium compared with the reference tool, measured in terms of specificity, sensitivity and negative and positive predictive value (NPV/PPV). 
Inter-tester reliability was calculated using $\mathrm{k}$-statistics to measure the agreement between the two that used psCAM-ICU, and the results showed a high reliability of 0.79 (95 per cent confidence interval [CI]: 0.760.83). PsCAM-ICU also showed a specificity of 93 per cent (95 per cent CI: 92-95) and a sensitivity of 79 per cent (95 per cent CI: 75-81) in patients under two years of age.

Alvarez et al. assessed psCAM-ICU as being a reliable and valid assessment tool for children aged from six months to five years, and considered it fast, objective and easy to use (28). Traube et al. (31) validated the Cornell Assessment of Paediatric Delirium (CAPD) with a specificity of 67.7 per cent and sensitivity of 100 per cent.

Traube et al. regarded CAPD as a reliable and valid assessment tool for children aged o-21 years. The CAPD values are based on observations and assessments conducted by a nurse in the course of one shift. Scoring of observations made over time makes it possible to detect small changes in a child's behaviour, and assessment once per shift is recommended (31).

CAPD and psCAM-ICU must be objective and have a clear cut-off point for delirium $(28,31)$. CAPD was used in the multi-centre study of Traube et al. (24) and the case series of Groves et al. (26).

In the study of Ista et al. (25), the nurses assessed the use of the delirium component, which is part of the Sophia Observation Withdrawal Symptoms scale (SOS-PD) and the Paediatric Delirium scale (PD) compared with a diagnosis of delirium made by a psychiatrist. SOS-PD was considered to be valid and reliable when used by nurses, with a sensitivity of 92.3 per cent and specificity of 96.5 per cent. 
Pearson's correlation value between the PD scale and CAPD was 0.89 (95 per cent CI: $0.82-0.93, \mathrm{p}<0.001$ ). The study also concluded that the scale was reliable, with inter-test reliability (intra-class correlation coefficient value [ICC]) of 0.99 (95 per cent, CI: 0.980.99) between nurse and researcher.

\section{Result of quality review}

Included studies were scored using design-specific checklists (cohort studies, case series, prevalence study and diagnostic test study) from Joanna Briggs Institute (22), where nine-twelve questions on quality were answered. We assessed the studies as being from medium to high quality (Appendix 1 [in Norwegian]).

\section{Discussion}

The aim of this systematic review is to sum up what the research literature reveals about the prevalence, symptoms and observations of delirium and the use of tools for assessing delirium in sick infants and children under two years of age who are admitted to neonatal or paediatric ICUs.

\section{Prevalence}

The included studies show great variation in the prevalence of delirium in this patient group $(24,25,27-$ 29). The variation may be due to the fact that Traube et al. (24) only conducted one assessment round on the actual day of the study, while Smith et al. (28) and Alvarez et al. (27) conducted several assessment rounds over a longer period and found higher prevalences. Delirium fluctuates, and the children may not have been delirious when the assessment rounds were conducted (24).

Daily assessment over a longer period might have detected more delirious children $(27,28)$. In the study of Ista et al., however, nurses used the SOS-PD scale at least three times a day - once on each shift - but still found very low prevalences. 


\section{«Daily assessment over a longer period might have detected more delirious children.»}

It is a strength that Traube et al. (24) conducted their study on 25 paediatric ICUs in five countries, while Ista et al. (25) collected data at four paediatric ICUs in the Netherlands. Multiple study sites can make results more generalisable than a single one (24).

Local differences across departments and global differences across countries may lead to different interpretations of the symptoms of delirium, which may affect results. The multi-centre studies $(24,25)$ reported the lowest prevalence of delirium in the included articles.

The paediatric ICU study (27) differs from the other studies in that it divides the study population into a separate age group for infants under one year of age and those aged 1-5 years. The other studies have age groups from o-2 years $(24,25,27-29)$.

These different groupings mean that the results are not fully comparable. In several of the study subjects who developed delirium, the condition quickly subsided. This may be due to anaesthesia emergency delirium, because many of the children had recently undergone surgery, and the high prevalence may be a result of a mixture of delirium and emergency delirium after anaesthesia (27).

\section{«One may wonder whether the included studies have captured all delirious children.»}

Given the great variation in reported prevalence, there may be hidden figures. The prevalence among adult intubated intensive care patients is almost 80 per cent (1). One may wonder whether the included studies have captured all delirious children. The results of the assessments and the paediatric psychiatry assessment may be affected by the fact that they were only performed in the daytime. 


\section{Symptoms}

Symptoms of delirium are mentioned in two studies $(26,30)$ which describe several symptoms of delirium that are consistent with the diagnostic criteria (11). When a nurse observes sick infants or children under two years of age who present individual or multiple symptoms of delirium, the symptoms may be misinterpreted as pain, discomfort, withdrawal, nausea or a desire to change position.

The behaviour that accompanies hyperactive delirium can be harmful. Children may fight against respiratory support, which may lead to a fall in oxygen saturation and higher pulse and blood pressure. The behaviour may also entail a risk of extubation and self-removal of other medical equipment $(9,26)$.

In such cases, the nurse or parents attempt to console the child. Non-medical interventions can provide reassurance, and usually help to calm restless children, but they are not always effective in cases of delirium (26). Opiates or benzodiazepines are then often administered, with varying effect $(26,30)$.

One study found that children treated with benzodiazepines had a five times greater risk of developing delirium (6). The same study found that delirium was a more certain predictor of mortality than a Paediatric Index of Mortality 3 score. Delirium may therefore be an early warning sign that the child's state is deteriorating further (6).

With greater knowledge about factors that precipitate and maintain delirium, the nurse can help to protect children by shielding the child's sleeping periods and ensuring that it is quiet and dark, and that the child is not disturbed (16).

\section{«Sick infants and children under two years of age with hypoactive delirium are possibly in greater danger of not being diagnosed.»}


Sick infants and children under two years of age with hypoactive delirium are possibly in greater danger of not being diagnosed. They are quiet and amenable as though they are sleeping or dozing. When they are awake, their eyes look tired. Vital parameters are stable, with little risk of extubation or self-removal of medical equipment (9).

Experience shows that such a condition can lead parents and the treatment team to conclude that the child has had good sleeping periods and little discomfort. None of the included studies have described symptoms of hypoactive or mixed delirium. In view of the possible outcome of undetected delirium, this is problematic. It reveals a need for more knowledge about delirium among health professionals and for a structured assessment form for detecting different types of delirium.

Infants who are difficult to sedate, are agitated and breath counter to the ventilator, are often treated with increasing doses of medication. At the same time, few neonatologists consider delirium a probable diagnosis (26). Symptoms of delirium and other conditions can be confused, and it may result in small children being subjected to unnecessary testing, having a poorer neurological outcome and a longer stay in hospital (3, 4).

In a worst-case scenario, the consequence of untreated delirium may be that the child dies (6). Silver et al. (29) found a greater risk of delirium in children who received extra oxygen, and the highest risk in intubated children. This finding is consistent with research on adults (32) and may indicate which children need extra attention from the nurse. 
A child is part of a family, and the parents are the child's primary caregivers and must be a natural part of the team surrounding the child. Parents need and wish to be with their child as much as possible (33). Health professionals can help parents by including them in the nursing of the child, providing information and supporting the way they cope with the situation (34).

It is usually the parents who spend most time with the child, and if their observations are acknowledged by the health professionals, this may be important for getting treatment started early. In cases of young children with delirium, it is often the parents who recognise the change in the child's behaviour and cognition $(2,26)$.

In different studies $(2,26,30)$, infants and children under two years of age were treated with antipsychotics. Little is known of the effect early exposure to psychotics may have on a child's further development (26). Deciding how delirium should be treated may therefore be an ethical dilemma.

The most important factor in preventing delirium in adults has proved to be an interdisciplinary team with expertise and a focus on cooperation. Several precautionary factors such as early mobilisation, reduction of invasive procedures, better nutrition and attention to sleep and pain relief also had a perceptible effect (35).

Some of these measures can be applied to the neonatal and paediatric context, as duration of stay, ventilator treatment, vasopressor treatment and physical restraints were all risk factors in this population (24, 27). 
The organisation of most neonatal and paediatric ICUs is based on the principles of family-centred care, and for neonatal units in particular, a key principle is adjustment of care to developmental stage. A holistic approach of this kind is founded on evidence-based knowledge of what promotes a child's development and health, and describes a practice designed to involve the family in all aspects of care for the child $(36,37)$.

These care principles ensure the family's involvement, and that the child has its carers available. They also ensure a better adapted external environment that to some extent can act as a counterweight to stress, pain and lack of loving close contact.

\section{Assessment tools}

With respect to the research question concerning the assessment tools used to detect delirium, three tools were tested in the included studies, with somewhat varying results.

CAPD has a high sensitivity and somewhat lower specificity, while the opposite applies to psCAM-ICU. We concluded that SOS-PD had both sensitivity and specificity. CAPD has been validated for neonates, while psCAM-ICU has been validated for infants from six months old $(28,31)$, and SOS-PD has been validated for infants from three months old (25).

CAPD comes with a guide that establishes normal development and behaviour for the age groups neonates, four weeks, eight weeks, 28 weeks, one year and two years. PsCAM-ICU has inattention as a point in the algorithm. Smith et al. therefore believe that this assessment tool is more appropriate than CAPD (28, $31)$.

\section{«The advantages of assessment tools are that the observations are systematic, and that the questions to be answered are clear.»}


Correct use of assessment tools depends on the persons who are going to perform the assessment having a knowledge of children's normal development and behaviour, and of symptoms of delirium. Comprehensive training and implementation procedures can ensure correct and more aware use. The advantages of assessment tools are that the observations are systematic, and that the questions to be answered are clear $(28,31)$.

The assessments are subjective, nonetheless; for example it is not easy to assess eye contact. Experience shows that the reported results of an objective assessment form are more readily accepted than the subjective observations and opinions of a nurse (9).

One possible drawback of an assessment tool is that the observations made of the patient do not always correspond to the points defined in the tool, and can be misunderstood or misinterpreted. Knowledge of why it is important to score children on delirium, and of how to use the assessment tool accurately, is a necessary part of nursing. Examples of barriers to achieving this are insufficient knowledge and time, and complicated assessment tools (9).

Nurses at a paediatric ICU did not complete the assessment or forgot to score if they had an acutely and/or critically ill patient. The study also showed that other nursing documentation was given priority ahead of assessment for delirium, and as a result the assessment was not performed (38).

The decision as to which assessment tool to use must be taken at departmental level, depending on need and patient group. The results show that CAPD covers neonates, in contrast to psCAM-ICU and SOS-PD. CAPD has a guide for normal behaviour and development, which can make assessment simpler. 
However, it can be of advantage to have an assessment tool that can be used for all patients, irrespective of age. CAPD or SOS-PD may therefore be most appropriate for several reasons. In light of the results of the studies, it appears nonetheless as though keen observation and delirium screening as part of standard nursing measures for small children who are admitted to neonatal or paediatric ICUs can contribute to early diagnosis of delirium (39).

\section{Strengths and weaknesses of the study}

The contribution and reliability of systematic reviews depend most on the quality of the original publications and the stringency of the methodology. This study is methodologically strong as a result of the broad-based literature search in four databases without restrictions on dates or study design, and because selection and quality control were carried out individually and blinded by three of the authors.

It is also a strength that most studies scored well on methodological quality. The database search specifically targeted intensive care for children in combination with delirium, which may appear narrow, but the keywords we used cover the subject, and an extensive text word search picked up articles that might otherwise have been missed.

The language restrictions introduced a risk of bias, but very few articles were excluded as a result of this restriction. We only included eight studies, which suggests that research in this field is rare.

The protocol was not registered in Prospero.org, a database for systematic review articles, and this is a weakness that may increase publication bias. The reason is that the project started as a master's project, and Prospero does not accept student studies. 


\section{Implications for practice}

There is a need for more research on the prevalence, symptoms and observations of delirium for the observed patient group. Good screening tools do exist, but must be implemented systematically, and more systematic assessment may contribute to new knowledge and new research results.

In the meantime, health professionals who work with this patient group should use existing tools and knowledge to prevent factors that precipitate and maintain delirium.

\section{Conclusion}

There is great variation in the studies on the prevalence of delirium in children under two years of age, but the results show that a relatively large proportion of children in this age group may develop delirium. The variation may indicate that it is difficult to diagnose delirium in this age group.

More knowledge of the symptoms of delirium in this vulnerable patient group may lead to a better neurological outcome and prevent unnecessary testing, shorten hospital stays and lower mortality. Implementation of and instruction in the use of validated screening tools can help to ensure that delirium is detected and treated earlier.

Nurses cooperating with the child's parents are probably those best fitted to observe whether the child's behaviour and cognition have changed and to perform the assessment optimally. Good continuity in the nursing group and rest of the child's treatment team can ensure early recognition of delirium.

\section{References}

1. Barr J, Fraser GL, Puntillo K, Ely EW, Gélinas C, Dasta JF, et al. Clinical practice guidelines for the management of pain, agitation, and delirium in adult patients in the intensive care unit. Crit Care Med. 2013;41(1):263-306. 
2. Edwards LE, Hutchison LB, Hornik CD, Smith PB, Cotten CM, Bidegain M. A case of infant delirium in the neonatal intensive care unit. J Neonatal Perinatal Med. 2017;10(1):119-23.

3. Smeets IAP, Tan EYL, Vossen HGM, Leroy PLJM, Lousberg RHB, Van Os J, et al. Prolonged stay at the paediatric intensive care unit associated with paediatric delirium. Eur Child Adolesc Psychiatry. 2010;19(4):389-93.

4. Madden K, Turkel S, Jacobson J, Epstein D, Moromisato DY. Recurrent delirium after surgery for congenital heart disease in an infant. Pediatr Crit Care Med. 2011;12(6):e413-5.

5. Schieveld JN. On pediatric delirium and the use of the Pediatric Confusion Assessment Method for the Intensive Care Unit. Crit Care Med. 2011;39(1):220-1.

6. Traube C, Silver G, Gerber LM, Kaur S, Mauer EA, Kerson A, et al. Delirium and mortality in critically ill children: epidemiology and outcomes of pediatric delirium. Crit Care Med. 2017;45(5):891-8.

7. Coughlin ME. Transformative nursing in the NICU - Trauma-informed age-appropriate care. New York: Springer Publishing Company; 2014.

8. Bettany-Saltikov J, McSherry, R. How to do a systematic literature review in nursing. A step by step guide. 2. utgave London: Open University Press; 2016.

9. Flaigle MC, Ascenzi J, Kudchadkar SR. Identifying barriers to delirium screening and prevention in the pediatric ICU: evaluation of PICU staff knowledge. J Pediatr Nurs. 2016;31(1):81-4.

10. Silver G, Kearney J, Traube C, Hertzig M. Delirium screening anchored in child development: The Cornell Assessment for Pediatric Delirium. Palliative \& Supportive Care. 2015;13(4):1005-11. 
11. Silver GH, Kearney JA, Kutko MC, Bartell AS.

Infant delirium in pediatric critical care settings. Am J Psychiatry. 2010;167(10):1172-7.

12. Holly C, Cantwell ER, Jadotte Y. Acute delirium: differentiation and care. Crit Care Nurs Clin North Am. 2012;24(1):131.

13. Ely EW, Inouye SK, Bernard GR, Gordon S, Francis J, May L, et al. Delirium in mechanically ventilated patients: validity and reliability of the confusion assessment method for the intensive care unit (CAM-ICU). JAMA. 2001;286(21):2703-10.

14. Malas N, Brahmbhatt K, McDermott C, Smith A, Ortiz-Aguayo R, Turkel S. Pediatric delirium: evaluation, management, and special considerations. Current Psychiatry Reports. 2017;19(9):65.

15. Harris J, Ramelet AS, van Dijk M, Pokorna P, Wielenga J, Tume L, et al. Clinical recommendations for pain, sedation, withdrawal and delirium assessment in critically ill infants and children: an ESPNIC position statement for healthcare professionals. Intensive Care Med. 2016;42(6):972-86.

16. Porter S. Infants with delirium: a primer on prevention, recognition, and management. Pediatr Nurs. 2016;42(5):223-9.

17. Bettencourt A, Mullen JE. Delirium in children: identification, prevention, and management. Crit Care Nurse. 2017;37(3):e9-18.

18. Polit DF, Beck CT. Nursing research. Generating and assessing evidence for nursing practice. 1oth ed. Philadelphia: Wolters Kluwer; 2017.

19. Grant MJ, Booth A. A typology of reviews: an analysis of 14 review types and associated methodologies. Health Information \& Libraries Journal. 2009;26(2):91-108. 
20. Booth A, Sutton A, Papaioannou D. Systematic approaches to a successful literature review. 2nd ed. London: SAGE Publications; 2016.

21. Higgins JP, Altman DG, Gøtzsche PC, Jüni P, Moher D, Oxman AD, et al. The Cochrane Collaboration's tool for assessing risk of bias in randomised trials. BMJ. 2011;343:d5928.

22. Joanna Briggs Institute. Critical appraisal tools. Adelaide: Joanna Briggs Institute. Available at:

https://jbi.global/critical-appraisal-tools (downloaded 20.04.2020).

23. Moher D, Liberati A, Tetzlaff J, Altman DG. Preferred reporting items for systematic reviews and meta-analyses: the PRISMA statement. Ann Intern Med. 2009;151(4):264-9.

24. Traube C, Silver G, Reeder RW, Doyle H, Hegel E, Wolfe HA, et al. Delirium in critically ill children: an international point prevalence study. Crit Care Med. 2017;45(4):584-90.

25. Ista E, Van Beusekom B, Van Rosmalen J, Kneyber MCJ, Lemson J, Brouwers A, et al. Validation of the SOS-PD scale for assessment of pediatric delirium: a multicenter study. Critical Care. 2018;22(1).

26. Groves A, Traube C, Silver GJP. Detection and management of delirium in the neonatal unit: a case series. 2016;137(3):e20153369.

27. Alvarez RV, Palmer C, Czaja AS, Peyton C, Silver G, Traube C, et al. Delirium is a common and early finding in patients in the Pediatric Cardiac Intensive Care Unit. The Journal of Pediatrics. 2018;195:206-12. 
28. Smith HAB, Gangopadhyay M, Goben CM, Jacobowski NL, Chestnut MH, Savage S, et al. The Preschool Confusion Assessment Method for the ICU: valid and reliable delirium monitoring for critically ill infants and children. Crit Care Med. 2016;44(3):592600.

29. Silver G, Traube C, Gerber LM, Sun X, Kearney J, Patel A, et al. Pediatric delirium and associated risk factors: a single-center prospective observational study. Pediatric Critical Care Medicine. 2015;16(4):303.

30. Schieveld JNM, Leroy PLJM, Van Os J, Nicolai J, Vos GD, Leentjens AFG. Pediatric delirium in critical illness: phenomenology, clinical correlates and treatment response in 40 cases in the pediatric intensive care unit. Intensive Care Med. 2007;33(6):1033-40.

31. Traube C, Silver G, Kearney J, Patel A, Atkinson TM, Yoon MJ, et al. Cornell Assessment of Pediatric Delirium: a valid, rapid, observational tool for screening delirium in the PICU. Crit Care Med. 2014;42(3):656-63.

32. Williams ST. Pathophysiology of encephalopathy and delirium. J Clin Neurophysiol. 2013;30(5):435-7.

33. Hall EO. Being in an alien world: Danish parents' lived experiences when a newborn or small child is critically ill. Scand J Caring Sci. 2005;19(3):179-85.

34. Smith VC, SteelFisher GK, Salhi C, Shen LY. Coping with the neonatal intensive care unit experience: parents' strategies and views of staff support. The Journal of Perinatal \& Neonatal Nursing. 2012;26(4):343-52.

35. Khan A, Boukrina O, Oh-Park M, Flanagan NA, Singh M, Oldham M. Preventing delirium takes a village: systematic review and meta-analysis of delirium preventive models of care. J Hosp Med. 2019;14:E1-7. 
36. Westrup B. Family-centered developmentally supportive care. NeoReviews. 2014;15(8):e325-35.

37. Roué J-M, Kuhn P, Maestro ML, Maastrup RA, Mitanchez D, Westrup B, et al. Eight principles for patient-centred and family-centred care for newborns in the neonatal intensive care unit. Archives of Disease in Childhood-Fetal and Neonatal Edition. 2017;102(4):F364-8.

38. Rohlik GM, Fryer KR, Tripathi S, Duncan JM, Coon HL, Padhya DR, et al. Overcoming barriers to delirium screening in the Pediatric Intensive Care Unit. Crit Care Nurse. 2018;38(4):57-67.

39. Silver G, Traube C, Kearney J, Kelly D, Yoon MJ, Moyal WN, et al. Detecting pediatric delirium:

development of a rapid observational assessment tool. Intensive Care Med. 2012;38(6):1025-31. 